\title{
EFECTO DEL SELENIO EN RATONES CON CÁNCER EXPERIMENTAL INDUCIDO CON SARCOMA 180
}

\author{
Eloísa M. Hernández F.; Elena R. Benavides R.; José J. Díaz B.; Rodolfo Huguet T. \\ Instituto de Investigación de Química Biológica, Microbiología y Biotecnología "Marco Antonio Garrido \\ Malo". Facultad de Farmacia y Bioquímica. UNMSM".
}

\begin{abstract}
RESUMEN
En un diseño experimental de tipo longitudinal, se delerminó el efectu anticancerígeno del Selenio frente a Sarcoma 180 inoculado a ratones hembras cepa Balb C53 de euatro semanas de nacido. Los parámetros cvaluados fueron: incremento de peso del tumor ( $\mathrm{n}=20$ ratones), actividad Catalasa (CAT), actividad Superóxido Dimutasa (SOD) y el tiempo de supervivencia. La dosis de selenio $7,36 \mathrm{ug} / \mathrm{Kg}$ peso/día se administró vía oral y fue previamente ensayada durante 120 días en ratones. Los resultados revelaron que el Selenio sólo incrementó en cinco días el período de supervivencia del $13 \%$ de los animales de experimentación ( $n=15)$; no tuvo efecto en reducir el peso del tumor; la actividad de CAT U/g Hb en el grupo de ratones inoculados con Sarcoma y que ingerían dieta normal fue de 802.4, en el grupo que recibió el Selenio fue de $101.7: 5$ pero la diferencia no fue estadísticamente significativa; la diferencia entre el promedio de la actividad SOD en ratones inoculados con Sarcoma que ingerían la dieta normal $(470 \mathrm{U} / \mathrm{g} \mathrm{Hb})$ y el promedio de ratones inoculados con Sarcoma que ingerían la dieta suplementada con Selenio $(530 \mathrm{U} / \mathrm{g} \mathrm{Hb})$ si resultó estadísticamente significativa. A la dosis ingerida y al juzgar por la actividad SOD, el Selenio ha demostrado tener efeclo protector contra la tumorogenesis indueida por Sarcoma 180, aún cuando no tiene efecto significativo en prolongar el período de supervivencia de los animales de experimentación.
\end{abstract}

Palabras clave: Selenlo y cáncer; Selenio y efecto antitumoral; Selenio y actividad Catalasa; Selenio y actividad Superóxido Dismutasa.

\section{SUMMARY}

In a experimental design $f$ longitudinal type, it was determined the anticancerous effect of selenium against Sarcoma 180 inoculated to female mice of Balb C53 strain of 4 weeks age. The evaluated parameters were: tumor increasing weight ( $n=20$ mice), catalase activity (CAT), superoxide dismutatse activity (SOD) and survival time. The dose of selenium of $7.36 \mathrm{Ug} / \mathrm{Kg}$ of weight/ day was administred by oral via and it was previously assayed during 120 days in mice. The results revealed that Selenium only increased in five days, the period of survival from the percentage of experimental animals $(n=15)$; It did not have any effect in reducing tumor weight; the activity of CAT U/g Hb in the group of inoculated mice with sarcoma and the ones which ate a normal diet were 802.4, in the group that received Selenium was of 1017.5 but the difference was not statistically significant; the difference between the average of SOD activity in inoculated mice with sarcoma that ate the normal diet $(470 \mathrm{U} / \mathrm{g} \mathrm{Hb})$ and the average of inoculated mice with sarcoma that ate the supplemented diet with selenium $(530 \mathrm{U} / \mathrm{g} \mathrm{Hb})$ was resulted statistically significant. At a ingested dose and in terms of SOD activity of selenium, it has shown to have a protector effect against sarcoma 180 inducing tumorogenesis, even when it does not have a significant effect in extend survival period of experimental animals.

Key words: Selenium and cancer, selenium and antitumporous effect, selenium and Catalase activity, seleruium and Superoxide Dismutase activity.

\section{INTRODUCCIÓN}

En los organismos aerobios, se presenta la condición de estrés oxidativo base de una serie de aberraciones fisiológicas, tal como la carcinogénesis, la aterosclerosis y aún del envejecimiento ${ }^{(1)}$.

Estudios experimentales in vitro han demostrado que distintos compuestos de selenio inhiben la pro= liferación de células cancerígenas pero aún no se conoce cuál es el comportamiento de este elemento frente al cáncer ${ }^{(2,3,4,5,6)}$. El predominio de la actividad de Catalasa (CAT) y la de Superoxido Dismutasa (SOD) nos indicaría un efecto protector contra la formación de tumores, por lo que es importante determinar la actividad de estas enzimas como parámetros de evaluación del posible efecto anticancerígeno del selenio.

1 Jr. Puno N. ${ }^{\circ} 1002$, Lịma 1 - Perú 
El presente trabajo se realizó con el objetivo de determinar el comportamiento anticancerígeno del selenio frente al sarcoma 180 inoculado a ratones hembras, tomando como parámetros: el desarrollo e incremento del peso del tumor, la actividad de dos enzimas antioxidantes: CAT y SOD y el tiempo de supervivencia.

\section{MATERIAL Y MÉTODOS}

Diseño Experimental. Es un estudio experimental de tipo longitudinal. Se emplearon ratones albinos hembras, cepa Balb C53, de 4 semanas de nacidos, adquiridos del Centro Nacional de Producción de Biológicos del Instituto Nacional de Salud. Cada uno fue colocado en jaulas individuales para ser asignados a cuatro estudios $(7)$ :

ESTUDIO "A". Se utilizaron 10 ratones hembras para determinar la dosis de selenio a utilizarse en los estudios B, C y D. Comprendió 120 días.

ESTUDIO "B". 80 ratones distribuidos en 4 grupos, 20 por cada grupo; para determinar el incremento del peso del tumor en los ratones inoculados con sarcoma 180. Los grupos fueron:

Grupo I: 20 ratones sin inoculación del sarcoma 180 y dieta normal.

Grupo II: 20 ratones con inoculación del sarcoma 180 y dieta normal.

Grupo III: 20 ratones sin inoculación del sarcoma 180 y dieta con suplemento de selenio.

Grupo IV: 20 ratones con inoculación del sarcoma 180 y dieta con suplemento de selenio.

El estudio tuvo una duración de 10 días después de la inoculación.

ESTUDIO " $\mathrm{C}$ ". 60 ratones distribuidos en 4 grupos, 15 por cada grupo; para determinar el tiempo de supervivencia. Los grupos fueron:

Grupo I: 15 ratones sin inoculación del sarcoma 180 y dieta normal.

Grupo II: 15 ratones con inoculación del sarcoma 180 y dieta normal.

Grupo III: 15 ratones sin inoculación del sarcoma 180 y dieta con suplemento de selenio.

Grupo IV: 15 ratones con inoculación del sarcoma 180 y dieta con suplemento de selenio.

ESTUDIO " $\mathrm{D}$ ". 20 ratones distribuidos en cuatro grupos, 5 por cada grupo, para determinar la acti- vidad de catalasa (CAT) y de superóxido dismutasa (SOD), así como la evaluación histopatológica del tumor. Los grupos fueron:

Grupo I: 5 ratones sin inoculación del sarcoma 180 y dieta normal.

Grupo II: 5 ratones con inoculación del sarcoma 180 y dieta normal.

Grupo III: 5 ratones sin inoculación del sarcoma 180 y dieta con suplemento de selenio.

Grupo IV: 5 ratones con inoculación del sarcoma 180 y dieta con suplemento de selenio.

Dieta normal. consistió en una mezcla de torta de soya, harina de trigo, aminoácidos sintéticos y an. tifúngicos, elaborada por la planta de alimentos de. Departamento de Nutrición de la Facultad de Zoo. tecnia de la Universidad Nacional Agraria.

Dieta con suplemento de selenio. Durante los días que comprendió cada estudio, se administró la dosis de selenio predeterminada $(7,36 \mu \mathrm{g} / \mathrm{Kg} /$ día $)$.

El estudio tuvo una duración de 12 días.

\section{MÉTODOS}

\section{El implante celular del Sarcoma 180}

Según Fernandinni y Vera ${ }^{(8)}$, las células del sarcom: 180 fueron obtenidas del NAMRID (Naval Medica Research Institute Detachment Lima); para pre servarlas se inoculaba en ratones hembras por ví subcutánea dentro del área inguinal izquierda. De sarrollado el tumor y antes que aparezcan síntoma: indicativos de deterioro en la salud del ratón (pela je desordenando y encrespado, disminución de $k$ locomoción), se procedió a sacrificar al animal po. degollamiento. Se extrajo el líquido ascítico, el cua se inoculaba a otro ratón hembra sano. La fuente de sarcoma fue un ratón hembra que había desarrolla do el tumor.

\section{La determinación de la dosis de Selenio/ (Estudio A}

Se tomó como referencia la recomendación diari para una mujer adulta de $60 \mathrm{~kg}$, que debe ser d $55 \mathrm{ug} /$ día ${ }^{(9)}$. l as dosis se administro por vía oral es $5 \mathrm{~mL}$ de agua destilada (promedio de agua previa mente determinada por el consumo de los mismo animales) y durante 120 días. El esquema se presen ta en la siguiente Tabla: 
TABLA 1: Dosis de Selenio Administrada a los Ratones hembras.

\begin{tabular}{|c|c|c|c|}
\hline \multirow{2}{*}{$\begin{array}{c}\text { Ratón } \\
\text { N. }^{*}\end{array}$} & \multirow{2}{*}{$\begin{array}{c}\text { Peso } \\
(\mathbf{g})\end{array}$} & \multicolumn{2}{|c|}{ Dosis de selenio } \\
\cline { 3 - 4 } & (ug/Kg)día & (ug)/día \\
\hline 1 & 24.5 & 0.00 & 0.000 \\
\hline 2 & 26.3 & $0.92^{*}$ & 0.024 \\
\hline 3 & 26.6 & 1.84 & 0.049 \\
\hline 4 & 25.7 & 3.68 & 0.095 \\
\hline 5 & 24.7 & 5.52 & 0.136 \\
\hline 6 & 25.6 & 7.36 & 0.188 \\
\hline 7 & 29.1 & 9.20 & 0.268 \\
\hline 8 & 26.5 & 11.04 & 0.293 \\
\hline 9 & 28.7 & 12.88 & 0.370 \\
\hline 10 & 26.1 & 14.72 & 0.384 \\
\hline
\end{tabular}

Dosis de referencia recomendada para una mujer adulta de $60 \mathrm{~kg}{ }^{i 18)}$.

Evaluación del desarrollo del sarcoma sobre la Base del Incremento de Peso (Estudio B)

a) Se registró el peso en cada uno de los grupos durante 20 días antes de la inoculación. Se comprobó mediante la prueba de Kolmogorov-Smirnov ${ }^{(10,11)}$ que los incrementos de peso seguían la distribución normal, y que presentaban homoscedasticidad, esto es, homogeneidad de varianzas, calculado con el paquete estadístico SPSS para Windows versión 10.0 .

b) Se implantó el sarcoma 180 como se describe anteriormente.

c) Durante los 10 días posteriores a la implantación se registró el peso de los animales. El incremento del peso del tumor se determinó por diferencia entre los pesos registrados al término de los 10 días y el peso antes de la implantación. Se estudiaron los efectos de dos factores: DIETA e INOCULACION, sobre la variable incremento de peso del tumor en animales de laboratorio. Se efectuó el análisis de varianza de dos criterios de clasificación de la variable ${ }^{(10,11)}$.

Todo resultado se consideró significativo si el valor correspondiente de $p<0.05$. El análisis estadístico se realizó por medio del paquete estadístico SPSS para Windows versión 10.0.

Evaluación de la supervivencia (Estudio C). Según el método de Kaplan-Meier ${ }^{(10,11,12)}$.

a) Fundamento: La ocurrencia del evento (muerte) en función del tiempo $t$, se registró en la curva de supervivencia. Esta registra el evento de manera continua desde un máximo de 1 cuando $t$ es igual a 0 y decrece cada vez que se registra el evento. La gráfica resultante tiene la forma de una escalera.

La diferencia entre los promedios de los tiempos de supervivencia se determinó mediante la prueba de significación aplicando los métodos de comparación global de supervivencia de Log Rank, Breslow y Tarone-Wareel, ${ }^{(10,1)}$ utilizando el paquete estadístico SPSS para Windows versión 10.0.

b) Procedimiento. Se empieza a administrar el selenio desde el momento de la inoculación y se prosigue con la evaluación de la supervivencia registrando el tiempo en que ocurre una muerte.

Actividad de la enzima catalasa (CAT). (Estudio D). Según N.U. Bergmeyer ${ }^{(13)}$. Se sacrificó a los ratones en estudio por degollamiento al décimo segundo día posterior a la inoculación del tumor, obteniéndose aproximadamente de 1 a $2 \mathrm{~mL}$ de sangre, de los cuales una parte se recolectó en un frasco con anticoagulante de Wintrobe $(0,2 \mathrm{~mL}$ desecado a 37 grados centígrados) y otra se destinó para la cuantificación de la hemoglobina $(\mathrm{g} \mathrm{Hb} \%)^{(14)}$.

a) Fundamento: Según $H$. U. Bergmeyer ${ }^{(13)}$, la absorción ultravioleta de una solución de peróxido de hidrógeno puedẹ ser fácilmente medida a 240 $\mathrm{nm}$. Durante la descomposición del peróxido con Catalasa, la absorción decrece con el tiempo y a partir de esa disminución, la actividad de la enzima puede ser calculada.

$$
\mathrm{H}_{2} \mathrm{O}_{2}+\mathrm{H}_{2} \mathrm{O}_{2} \stackrel{\text { CAT }}{\longrightarrow} \mathrm{O}_{2}+2 \mathrm{H}_{2} \mathrm{O}
$$

b) Reactivos.

1. Buffer Fosfato de potasio $0.05 \mathrm{M} \mathrm{pH} 7.0$

2. Sustrato: solución de peróxido de hidrógeno $0.05 \%$. Diluir $0.2 \mathrm{~mL}$ de $\mathrm{H}_{2} \mathrm{O}_{2}$ grado reactivo en $100 \mathrm{~mL}$ de buffer fosfato de potasio $0.05 \mathrm{M} \mathrm{pH}$ 7.0.

c) Preparación de la muestra. La sangre obtenida se diluyó en agua destilada 1 en 12 volúmenes y se enfrió a $4{ }^{\circ} \mathrm{C}$ durante 5 minutos para producir hemólisis y así liberar la cnzima del eritrocito.

d) Procedimiento: En una celda de cuarzo de $1 \mathrm{~cm}$ de paso de luz se pipetea $2.9 \mathrm{~mL}$ de peróxido diluído al $0.05 \%$. Se incubó a $25^{\circ} \mathrm{C}$ por 5 minutos. Se procedió a medir la absorbancia a $240 \mathrm{~nm}$, 
que debe estar entre $0.500-0.550$. Adicionar la muestra de sangre procesada y leer las absorbancias cada 15 segundos durante 3 minutos, controlados desde que se agrega la muestra. Determinar la variación de absorbancia por minuto $(\Delta \mathrm{A} / \mathrm{min})$.

e) Cálculos

$u C A T / m L$ sangre $=\frac{(\Delta \mathrm{A} / \mathrm{min} \times 1000)}{43.6 \times \mathrm{mL} \text { de sangre en cada } \mathrm{mL} \text { de muestra reactiva }}$

$\mathrm{UCAT} / \mathrm{g} \mathrm{Hb}=\mathrm{UCAT} / \mathrm{mL}$ de sangre $\times 100 / \mathrm{g} \mathrm{Hh} \%$

f) Efecto del factor dieta e inoculación sobre actividad CAT

Obtenido los datos y los promedios de cada grupo se efectuó el análisis de varianza de dos criterios de clasificación de la variable ${ }^{(10,11)}$. Todo resultado se consideró significativo si el valor correspondiente de $\mathrm{p}<0.05$. El análisis se realizó por medio del paquete estadístico SPSS para Windows versión 10.0 .

Actividad de la Enzima Superóxido Dismutasa (SOD). Método de Misra HP. And Fridich $I^{(15)}$. Lopez VL y Robles BY ${ }^{(16)}$

a) Fundamentos. La capacidad de Superóxido Dismutasa de inhibir la autooxidación de la epinefrina a adenocromo, a un $\mathrm{pH}$ de 10.2. La oxidación es medida a una longitud de onda de 480 $\mathrm{nm}$ correspondiente al adenocromo.

b) Reactivos.

1. Epinefrina $5 \mathrm{mg} / \mathrm{mL}$ pH 2.0 (solución acuosa)

2. Buffer carbonato de sodio $0.05 \mathrm{M} \mathrm{pH} 10.2$

c) Obtención y preparación de la muestra. Se realizó de manera ya indicada en la determinación de CAT.

d) Procedimiento. En una cubeta de cuarzo de $1 \mathrm{~cm}$ de paso de luz: $2.9 \mathrm{~mL}$ del buffer (carbonato de sodio $0.05 \mathrm{M}$ y EDTA $0.0001 \mathrm{M}), 0.03 \mathrm{~mL}$ de epinefrina, y $0.025 \mathrm{~mL}$ de muestra procesada. Las lecturas se hacen a $480 \mathrm{~nm}$ y a $37^{\circ} \mathrm{C}$, se lee la absorbancia al minuto $\left(A_{1}\right)$ y al tercer minuto $\left(A_{2}\right)$. Es necesario la preparación de un blanco. La concentración de SOD se mide por su \% de inhibición frente a la oxidación de la epinefrina.

e) Cálculos

$$
\underline{A_{2}-A_{1}}=\Delta A / \text { minuto del control o de la muestra }
$$

2.

Índice del blanco o control $=$ Índice de reacción sin inhibir $=100 \%$
$1 \mathrm{USOD}=$ mitad de la $\triangle \mathrm{A} /$ minuto del blanco ${ }^{(17)}$

$\mathrm{USOD} / \mathrm{mL}$ de sangre $=$ USOD de la muestra $\times$ factor de dilución

$\mathrm{U} \mathrm{SOD} / \mathrm{g} \mathrm{Hb}=\mathrm{U}$ SOD $/ \mathrm{mL}$ de sangre $x \frac{100}{\mathrm{~g} \text { de } \mathrm{Hb} \%}$

El Factor de dilución fue: 48

f) Efecto de los Factores dieta e inoculación sobre la actividad SOD

Con los datos y promedios de cada grupo, se efectuó el análisis de varianza con dos criterios de clasificación de la variable ${ }^{(10,11)}$.

Todo resultado se considera significativo si el valor correspondiente de $\mathrm{p}<0.05$. El análisis se realizó por medio del paquete estadístico SPSS para Windows versión 10.0 .

\section{Evaluación Histopatológica}

Sacrificados los ratones del estudio " $\mathrm{D}$ ", se procedió a hacer la disección del animal para extraer hígado, páncreas y riñón, estos se colocaron en frascos conteniendo $10 \mathrm{~mL}$ de formol de $10 \%$. En a ta Facultad de Medicina Veterinaria, UNMSM se realizó estudio histopatológico.

\section{RESULTADOS}

1. Diferenciación de la dosis de Selenio - (Estudio A). Según el esquema mostrado en la Tabla 1 y debido que al término de 120 días, ninguno de los animales mostró signos de debilidad, enfermedad o haya muerto, la dosis seleccionada para los estudios B, C y D fue $7.36 \mu \mathrm{g} / \mathrm{Kg} /$ día dosis 8 veces superior a la requerida para una mujer adulta de $60 \mathrm{Kg}$ que es de $0.92 \mu \mathrm{g} / \mathrm{kg}$ de peso corporal por día.

2. Incremento de peso del tumor (Estudio B) (Gráfico 1) Los valores antes de la inoculación estuvieron entre 4.10 y $4.71 \mathrm{~g}$. las pruebas de normalidad (Tabla 2) y el test de homogeneidad (Tabla 3) indicaron que la variación entre pesos es no significativa.

Diez días después de la inoculación (Gráfico 2) los valores se incrementaron desde $4.4 \mathrm{~g}$ (Grupo III) a $7.75 \mathrm{~g}$ (Grupo IV). El efecto de la dieta no fue significativo $(\mathrm{F}=0.299)$ : $\mathrm{El}$ efecto inoculación si lo fue ( $\mathrm{F}=51.42$ ) (Tabla 4 ).

3. Evaluación de la supervivencia (Estudio C). Según los datos (Gráfico 3) después de los 33 días 


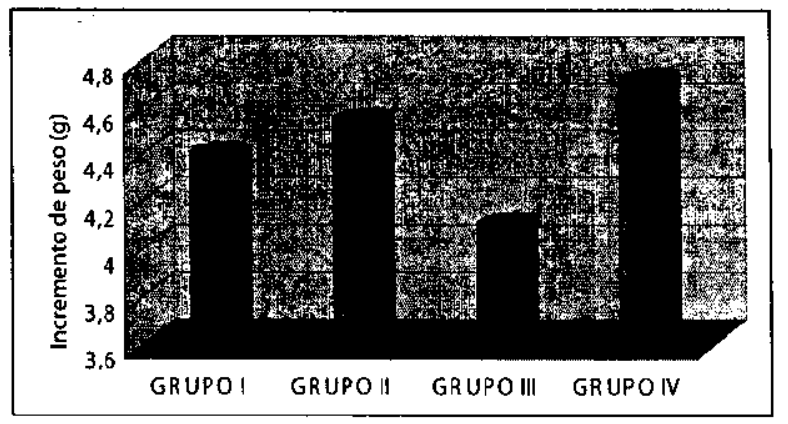

\begin{tabular}{|c|c|c|c|c|}
\hline Promedio & 4.40 & 4.54 & 4.10 & 4.71 \\
\hline $\begin{array}{l}\text { Desv. Est. } \\
\text { máx }\end{array}$ & 7.00 & 5.70 & 6.00 & 7.00 \\
\hline $\begin{array}{l}\text { Desv. Est. } \\
\text { min }\end{array}$ & 2.00 & 2.80 & 2.00 & 2.00 \\
\hline
\end{tabular}

Gráfico N. ${ }^{\circ} 1$. incremento promedio de pesos de ratones durante 20 días antes de la inoculación del sarcoma.

de implante del sarcoma 180 , solo sobrevivieron $2(13 \%)$ de los 15 animales que recibían la dieta con selenio; estos murieron a los 34 y 39 días.

4. Efecto de la Ingesta de Selenio sobre la Actividad de Catalasa (CAT) (Estudio D). En el gráfico 4 se observa que entre los grupos de animales inoculados con sarcoma 180 , los que recibían dieta con selenio presentaron mayor actividad $\mathrm{CAT}$, pero la diferencia no fue significativa.

5. Efecto de la ingesta de selenio sobre la actividad de Superóxido Dismutasa (SOD). En el gráfico 5 , se observa que entre los grupos de animales inoculados con sarcoma 180, los que recibían la dieta con selenio presentaron mayor actividad SOD, la diferencia entre los valores fue significativa.

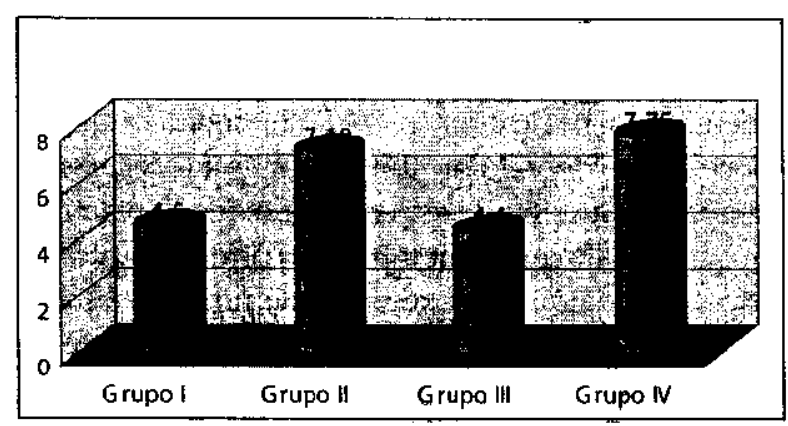

\begin{tabular}{|l|r|r|r|r|}
\hline Promedio & 4.5 & 7.19 & 4.40 & 7.75 \\
\hline Desv. Est. máx & 7.00 & 12.5 & 6.20 & 12.0 \\
\hline Desv. Est. min & 2.00 & 4.70 & 2.00 & 2.00 \\
\hline
\end{tabular}

Gráfico N. ${ }^{\circ}$ 2. Incremento de peso del tumor en ratones durante 10 días después de la inoculación del sarcoma.
Tabla N..$^{\circ}$. Prueba de normalidad del peso en los ratones durante 20 días antes de la inoculación.

\begin{tabular}{|c|c|c|c|}
\hline \multirow{2}{*}{ Grupo } & \multicolumn{3}{|c|}{ Prueba de Kolmogorov - Smirnov } \\
\cline { 2 - 4 } & Estadístico & gl & $\mathrm{p}$ \\
\hline Grupo I & .130 & 20 & $\mathrm{~ns}$ \\
\hline Grupo II & .111 & 20 & $\mathrm{~ns}$ \\
\hline Grupo III & .180 & 20 & $\mathrm{~ns}$ \\
\hline Grupo IV & .165 & 20 & $\mathrm{~ns}$ \\
\hline
\end{tabular}

Tabla N. ${ }^{\circ}$ 3. Test de homogeneidad de la varianza de los pesos.

\begin{tabular}{|l|r|r|r|r|}
\hline & $\begin{array}{c}\text { PRUEBA } \\
\text { DE } \\
\text { LEVENE }\end{array}$ & gl1 & gl2 & p \\
\hline Basado en la Media & 1.430 & 3 & 76 & $\mathrm{~ns}$ \\
\hline Basado en la Mediana & 1.194 & 3 & 76 & $\mathrm{~ns}$ \\
\hline $\begin{array}{l}\text { Basado en la Mediana y } \\
\text { con ajuste con gl }\end{array}$ & 1.194 & 3 & 68.381 & $\mathrm{~ns}$ \\
\hline $\begin{array}{l}\text { Basado en la media } \\
\text { recortada }\end{array}$ & 1.421 & 3 & 76 & $\mathrm{~ns}$ \\
\hline
\end{tabular}

Tabla N. ${ }^{\circ}$. prueba de efectos entre sujetos.

\begin{tabular}{|l|r|r|r|r|r|}
\hline \multicolumn{1}{|c|}{ Fuente } & $\begin{array}{c}\text { Suma } \\
\text { de Cua- } \\
\text { drados }\end{array}$ & $\mathbf{G l}$ & $\begin{array}{r}\text { Cua- } \\
\text { drado } \\
\text { Medio }\end{array}$ & F & p \\
\hline Dieta & 1.058 & 1 & 1.058 & .299 & $\mathrm{~ns}$ \\
\hline Inoculación & 181.804 & 1 & 181.804 & 51.42 & .000 \\
\hline $\begin{array}{l}\text { Dieta* ino- } \\
\text { culación }\end{array}$ & 2.178 & 1 & 2.178 & .616 & $\mathrm{~ns}$ \\
\hline Error & 268.695 & 76 & 3.535 & & \\
\hline
\end{tabular}

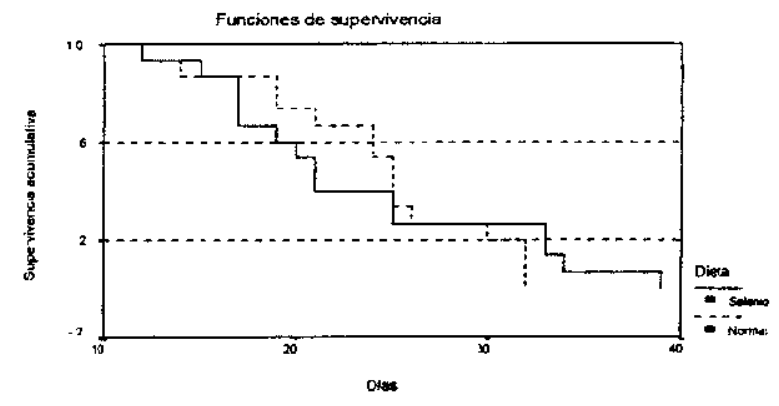

Gráfico $N .^{\circ}$ 3. Curva de supervivencia de los ratones hembras $(n=15)$ inoculados con sarcoma 180. 


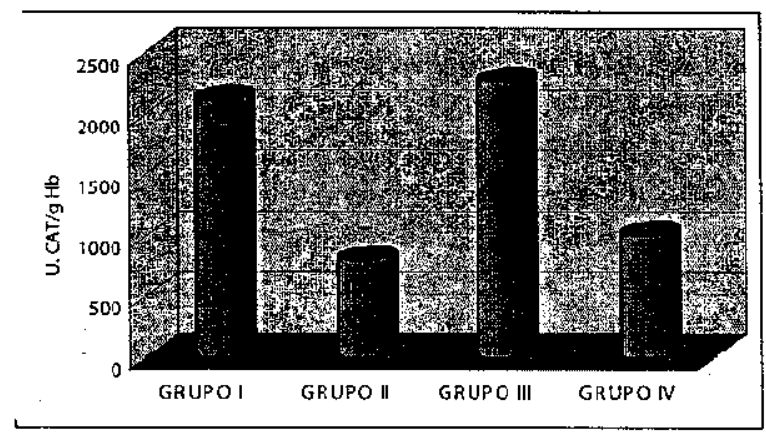

LEYENDA:

I. Sin sarcoma, dieta normal

II. Con sarcoma, dieta normal

III. Sin sarcoma dieta con Se

IV. Con sarcoma dieta con Se

\begin{tabular}{|c|c|c|}
\hline \multicolumn{3}{|c|}{ EFECTOS ENTRE SUJETOS } \\
\hline & Valor F & $\mathrm{P}$ \\
\hline Dieta (D) & 2.7 & n.s \\
\hline Inocularión (T) & 135.5 & .00 \\
\hline $\mathrm{DXI}$ & 0.08 & n.s. \\
\hline
\end{tabular}

\begin{tabular}{|l|r|r|r|r|}
\hline PROM. & $\mathbf{2 1 2 7 . 6 6}$ & $\mathbf{8 0 2 . 4}$ & $\mathbf{2 2 7 9 . 6 4}$ & $\mathbf{1 0 1 7 . 5 6}$ \\
\hline Desv. & 124.6 & 261.1 & 206.5 & 347.3 \\
\hline Máx. & 2276.0 & 1169.3 & 2517.0 & 1578.3 \\
\hline Mín. & 1991.4 & 485.3 & 2078.8 & 722.7 \\
\hline
\end{tabular}

Gráfico N..$^{\circ}$ 4. Efecto de la ingesta de selenio sobre la actividad de la enzima catalasa (U CAT/g HB) en ratones hembras.

\section{DISCUSIÓN}

La actividad anticancerigena del selenio ha sido atribuida no sólo a la acción antioxidante a través de selenoproteínas con capacidad enzimática antioxidante, sino que la principal actividad es causada por sus metabolitos, los cuales parecen que inhiben la formación de proteínas funcionales y factores de crecimiento en las células tumorales ${ }^{(17,18)}$.

El incremento de peso (Gráfico No 2 , Tabla 4) del tumor en el grupo inoculado es debido al incontrolable desarrollo celular que facilita un aumento del número de células. Por otro lado, no se observó un efecto inhibitorio del selenio sobre el desarrollo del sarcoma; asimismo no se observó incremento del tiempo de supervivencia (Gráfico $\mathrm{N}^{\circ}$ 3); debido a que posiblemente su capacidad carcinostática es superada por una rápida proliferación celular ${ }^{(19,20)}$.

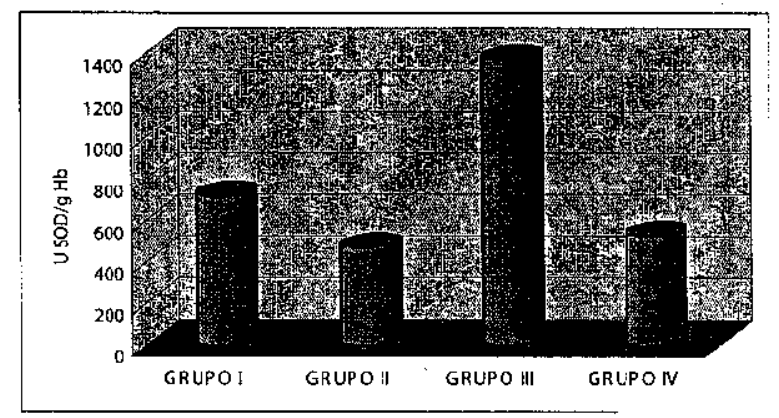

LEYENDA:

I. Sin sarcoma, dieta normal

II. Con sarcoma, dieta normal

III. Sin sarcoma dieta con Se

IV. Con sarcoma dieta con Se

\begin{tabular}{|l|r|r|}
\hline \multicolumn{3}{|c|}{ EFECTOS ENTRE SUJETOS } \\
\hline & Valor F & \multicolumn{1}{c|}{ P } \\
\hline Dieta (D) & 55.2 & 0.0 \\
\hline Inoculación (I) & 127.7 & .00 \\
\hline D X I & 38.2 & .00 \\
\hline
\end{tabular}

\begin{tabular}{|l|r|r|r|r|}
\hline \multicolumn{1}{|c|}{ PROM. } & $\mathbf{7 1 8 . 1 2}$ & $\mathbf{4 7 0 . 0 6}$ & $\mathbf{1 3 7 7 . 3 6}$ & $\mathbf{5 3 0 . 5 8}$ \\
\hline Desv. Est. & 63.7 & 44.2 & 173.4 & 104.0 \\
\hline Máx. & 826.5 & 534.7 & 1668.0 & 674.6 \\
\hline Mín. & 657.2 & 425.2 & 1220.3 & 394.2 \\
\hline
\end{tabular}

Gráfico $N^{\circ}{ }^{\circ}$. Efecto de la ingesta de selenio la actividad de la superoxidodimutasa (sod) en ratones hembras.

Con respecto a la actividad de CAT (Gráfico N. ${ }^{\circ} 4$ ). La acción antioxidante del selenio no influenció en un aumento significativo de CAT. Entre los gru pos no inoculados y los inoculados, sí se observô diferencia significativa ( $p<0.005)$, debido a que la inoculación de células tumorales y su desarrollo genera producción de especies de oxígeno reactivo, causando daño en la membrana y otros tejidos ${ }^{21,22\}}$. Esto ocasiona que en presencia de tumores la actividad de las enzimas del sistema antioxidante se encuentren disminuidas por producción de estrés oxidativo ${ }^{(23)}$. La diferencia entre las medias de los grupos inoculados: con suplemento de selenio y con dieta normal respectivamente, no fue significativa $(p<0.005)$ y demuestra que el selenio no influyć positivamente en el aumento de CAT en presencia de sarcoma 180, aunque la media del grupo suple mentado se encontraba ligeramente mayor. 
Con respecto a la actividad de la SOD (Gráfico 5): La variación significativa $(p>0,005)$, entre las medias de actividad deSOD de los grupos con dieta normal y los grupos con dieta suplementada demuestra la acción antioxidante del selenio y su importancia en la protección contra los radicales libres en enfermedades como el cáncer. Por otro lado, la diferencia significativa ( $p<0,005)$, entre las medias de los grupos inoculados: con dieta suplementada y con dieta normal respectivamente, evidencia el efecto protector del selenio frente al desarrollo del sarcoma 180, debido posiblemente a su acción antioxidante ${ }^{(23,24)}$.

Con respecto a la evaluación histopatológica del tumor: No hubo diferencias notables entre las células cancerígenas de los ratones con dieta suplementada y con dieta normal respectivamente, esto debido a que la proliferación tumoral y el deterioro sobre los tejidos es superior al efecto antioxidante del selenio. Es importante mencionar que no hubo diferencia notable sobre el estado de las células entre los grupos sin inoculación: suplementados y con dieta normal, respectivamente; demostrando que el selenio administrado no alteró el estado celular normal ${ }^{\{27}$. $28,29,30$ ).

En la administración de selenio a una dosis de 7.3 $u \mathrm{~g} / \mathrm{Kg}$ de peso corporal a ratones hembras cepa Balb C53, inoculados con sarcoma 180, no se observó efecto inhibitorio del selenio, sobre la evolución del tumor.

Se observó aumento no significativo de la actividad de catalasa y aumento estadísticamente significativo para la actividad de superoxido dismutasa, y no se evidenció tendencia a un mayor tiempo de supervivencia.

\section{REFERENCIAS BIBLIOGRAFICAS}

1. Montero $\mathbf{M}$. Los radicales libres y las defensas antioxidantes. Anales de la Facultad de Medicina de la UNMSM, Vol.57, N. ${ }^{\circ} 4-1996$ : p. 278281.

2. Armstrong B., Doll D. Environmetal National Research Council. Nutrition in Health and Diseases. Implications for reducing chronic disease risk. Int. J Cancer 1975; 15: 617-631.

3. Wu AH, Henderson BE, Pike MC. Smoking and other risk factors for lung cancer in women. J Natl Cancer Inst 1985; 74: 747-51.
4. Hunter DJ, Spiegelman D, Adami MO. Cohort studies of fat intake and the risk of breast cancer. N Engl J Med 1996; 334: 356-361.

5. Coates RJ, Weiss NS, Daling JR. Serum levels of selenium and retinol and the subsequent risk of cancer. Am J Epidemiol 1988; 128: 515-23.

6. Revista Panamericana de Salud Pública año 77, vol 4, $\mathrm{N}^{\circ} 4,1998$.

7. Drug information for the health care profesional. USP D1, 1995. 15 ${ }^{\mathrm{TH}}$ edición. Printed by Rand Mac Nally Taunton, Massachusetts 02780.

8. Fernandini R, L, Vera A, Influencia de una dieta suplementada con ácido ascórbico en el desarrollo del sarcoma inducido por implantación celular. Facultad de Farmacia y Bioquímica. UNMSM. Lima 1999.

9. Schrauzer GN. Nutritional selenium supplements: products types; quality, and safety. J Am Coll Nutr 2201 Feb; 20 (1): 1-4.

10. Camacho RJ. Estadística con SPSS (versión 9) para Windows. RA-MA Editorial. Madrid 2000.

11. Ferrar AM. SPSS para Windows. Análisis estadístico 1ra. ed, En: español McGraw-Hill/Interamericana de España, S.A.U. 2001.

12. Diccionario estadístico. Data Minino Institute. http://www.estadistico.com. Accesado 21 de junio de 2006.

13. Bergemeyer, H.U. Methods of Enzimatic Analysis, Vol 1, p 438, 1974, Academic Press, Nueva York.

14. Guerci A, "Laboratorio - Métodos de análisis clínicos". 3ra. edición, 1985. "El ateneo" editorial. Buenos Aires.

15. Misra HP and Fridich I. The role of superoxide anión in the autooxidación of epineplirine and a simple assay for superoxide dismutase". The Journal of Biological Chemistry Vol. 247, N. ${ }^{\circ} 10$, 1972. p. 3170.

16. López V., Robles B. Correlación entre los niveles de hemoglobina glicada y las enzimas antioxidantes en pacientes con diabetes mellitus tipo 2. UNMSM. Facultad de Farmacia y Bioquímica. 2000.

17. Schrauzer GN. Nutritional selenium supplements: products types, quality, and safety. J Am Coll Nutr 2001 Feb; 20(1): 1-4. 
18. Schrauger GN. Anticarcinogenic effects of selenium. Ceel mol Life Sci 2000 Dec; 57 (13-14): 1864-1873.

19. Lykkesfeldt J. et al. Ascorbic acid and dehydroascorbic acid as a biomarkers of oxidative stress caused by smoking. The American journal of Clinical Nutrition, 1997; 67 (4): 959-963.

20. TR-247 Carcinogenesis bioassay of L-ascorbic acid (vitamin C) (Cas No 50-81-7) in F344/N rats and B6C3F1 Mice (feed Study). Disponible en: http://ntp-server.niehs.nih.gov/htdocs/LTstudies/trt.

21. Isamat $\mathrm{M}$ et al. Regulación molecular de la invasión y de la metástasis. Serie monográfica. Editorial Sandoz Pharma, 1994; 2: 6-13.
22. Klauning J et al. The role of oxidative stress in chemicals carcinogenesis. Journal of the National Institute of Enviromental Health Perspective, 1998; 106 (sppl 1): 289-294.

23. Thirunavukkarasu C, Sakthisekaran D. Effects of selenium on $\mathrm{N}$-nitrosodiethylamine-induced multistage hepatocarcinogenesis with reference to lipid peroxidation and enzymatic antioxidant. Cell Biochem Funct 2001 mar; 19(1): 27-35.

24. Combs GF Jr. Chemopreventive mechanisms of sclenium. Med Klin 1999 Oct 15; 94 Combs GF Jr.: 18-24. 